\title{
Teorias econômicas de oferta de educação: evolução histórica, estado atual e perspectivas*
}

Fábio D. Waltenberg

Université Catholique de Louvain

Correpondência:

Fábio D. Waltenberg

Economics Department

Université Catholique de Louvain

3, Place Montesquieu (bureau d105)

B-1348 Louvain-la-Neuve - Bélgica

e-mail: waltenberg@ires.ucl.ac.be

\section{Resumo}

Este artigo preocupa-se com uma faceta particular (o lado da oferta) de uma das duas grandes linhas de pesquisa em economia da educação (aspectos econômicos dos sistemas educacionais). Apresentam-se a evolução histórica, o estado atual do debate e as perspectivas de desenvolvimento das teorias econômicas de oferta de educação, abarcando-se o período compreendido entre o início da década de 1960 e as contribuições mais recentes. Argumenta-se que as teorias tradicionais de economia da educação (capital humano e sinalização) não deram tratamento adequado ao lado da oferta da educação. Mais tarde, os conceitos e o instrumental da microeconomia da firma foram mobilizados a fim de se tentar mapear a "tecnologia de produção de educação". A abordagem das funções de produção de educação, baseadas inicialmente apenas em insumos monetários, não foi suficiente para que se apreendesse toda a complexidade envolvida no processo de provisão de educação. Uma análise de artigos mais recentes revela três caminhos promissores para o desenvolvimento das teorias de oferta de educação: (i) incluir insumos não monetários às funções de produção; (ii) levar em consideração aspectos institucionais e organizacionais do sistema educativo; e (iii) aprimorar as técnicas econométricas de estimação das funções de produção. Por fim, o artigo discute mais detidamente o primeiro desses três caminhos.

\section{Palavras-chave}

Economia da educação - Capital humano - Oferta de educação Funções de produção de educação.

* Pelo auxílio financeiro concedido, sou grato a dois programas de fomento à pesquisa da Comunidade Francesa da Bélgica: Action de Recherches Concertée - ARC 02/07-274 (GIRSEF) e Action de Recherches Concertée - ARC 03/08302 (Departamento de Economia). 


\title{
Economic theories of the supply of education: historical evolution, current state, and perspectives ${ }^{*}$
}

\author{
Fábio D. Waltenberg \\ Catholic University of Louvain
}

Contact:

Fábio D. Waltenberg

Economics Department

Université Catholique de Louvain

3, Place Montesquieu (bureau d105)

B-1348 Louvain-la-Neuve - Bélgica

e-mail: waltenberg@ires.ucl.ac.be

\begin{abstract}
The present article deals with a particular aspect (the side of the supply) of one of the two main lines of research in the economics of education (economical aspects of educational systems). It shows the historical evolution, the current state, and the perspectives of development of the economic theories of education supply, covering the period from the early 1960s to the more recent contributions. It argues that the traditional theories of the economics of education (human capital and screening) have not dealt adequately with the supply aspect of education. Later, the concepts and the instruments of microeconomics of the enterprise were mobilized to try and map out the "technology of production of education". The approach to the functions of production of education initially based just on monetary fluxes was not enough to apprehend all the complexity involved in the process of the supply of education. An analysis of more recent texts reveals three promising paths to the development of the theories of the supply of education: (i) inclusion of nonmonetary fluxes into the production functions; (ii) taking into account institutional and organizational aspects of the education system, and (iii) improvement of the econometric techniques for the estimation of the production functions. Lastly, the article discusses at more length the first of these paths.
\end{abstract}

\section{Keywords}

Economics of education - Human capital - Supply of education Production functions of education
*The author acknowledges the financial support of two research sponsoring programs of the French Community of Belgium: Action de Recherches Concertée - ARC 02/07-274 (GIRSEF) and Action de Recherches Concertée - ARC 03/08302 (Economics Department). 
Às contribuições pioneiras das teorias do capital humano na década de 1960, seguiram-se diversas linhas de pesquisa em economia da educação. Blaug (1992) classificou-as em dois campos principais: (a) análises do valor econômico da educação, isto é, a importância de medidas agregadas de educação para o crescimento de um país ou região; e (b) aspectos econômicos dos sistemas educacionais. Apesar de muitos trabalhos publicados desde então extrapolarem essa catalogação simples, ela ainda se revela útil para classificar grande parte das contribuições.

Na primeira linha de pesquisa que, segundo a classificação de Blaug, constitui um ponto de vista mais macroeconômico, os resultados empíricos foram e ainda são contraditórios. 0 desenvolvimento da nova teoria do crescimento incrementou o modelo de Robert Solow com novos conceitos (capital humano, learning-by-doing, pesquisa e desenvolvimento), ao longo das décadas de 1980 e 1990, dando novo fôlego a essa linha de pesquisa. De fato, os autores dessa escola chegaram à conclusão de que o crescimento econômico está estreitamente ligado ao nível de educação de um povo, ou seja, de que a educação é um importante fator de produção ${ }^{1}$.

Entretanto, são poucos os verdadeiros consensos além deste: não é possível estabelecer uma relação quantitativa direta entre educação e crescimento (há países que gastam bem mais do que outros em educação, mas crescem bem menos); ainda não foi possivel determinar um 'nível ótimo' de educação de um país (há uma vasta literatura tratando do problema de sobreeducação, por exemplo); suspeita-se, mas não se sabe ao certo, de que exista um patamar mínimo de escolaridade média da população ('treshold level'), a partir do qual um país entraria em 'rota de crescimento acelerado'; não se sabe qual é o tempo de 'maturação' nem de 'depreciação' do investimento em capital humano. Em um artigo recente, Rasera (1999) faz um balanço dos estudos nessa linha de pesquisa e resume a questão afirmando que as complexas relações entre educação e crescimento econômico dificilmente são apreendidas pelos estudos econométricos, em razão: (i) de sua complexidade, (ii) de seu caráter não generalizável e (iii) da não-independência entre as variáveis. Além disso, a educação, de modo geral, é mensurada de maneira grosseira, sem que se considere a sua qualidade. Em suma, é difícil tirar conclusões nessa ótica econômica agregada da educação, a não ser a de que educação 'importa' para fazer um país crescer².

A segunda linha de pesquisa, segundo a classificação de Blaug, preocupa-se em investigar aspectos econômicos dos sistemas educativos. De certa forma, trata-se de um nível de análise mais meso ou microeconômico, conforme se direcione o enfoque sobre o sistema como um todo ou sobre determinadas escolas que dele fazem parte. Pode-se também argumentar que o desempenho de um sistema educativo tenha efeitos macroeconômicos. Porém, de qualquer modo, o instrumental de análise de um sistema educativo é mais microeconômico e microeconométrico. Nesse nível, a preocupação não recai sobre a influência de níveis agregados de educação no crescimento econômico, mas sim sobre o modo de funcionamento dos sistemas educativos. Entre os temas tratados, incluem-se: análises de custos e benefícios privados e sociais (por nível de ensino, por tipo de currículo, por tipo de técnica pedagógica, por tipo de ensino - privado ou público - etc.), análises de eficiência na alocação de recursos, comparação entre modos de regulação e financiamento, definição de objetivos escolares e pós-escolares de sistemas educativos, avaliação de atingimento desses objetivos (em termos de eficácia e eqüidade, sobretudo) etc.

Nos últimos anos, a literatura de economia da educação tem concentrado esforços nessa segunda linha de pesquisa. Por exemplo, ao definir uma agenda de pesquisa para a economia da

1. Sobre a relação entre educação e crescimento econômico, ver os artigos de Paul Romer (1990) e Lucas (1988), o livro de Barro; Sala-i-Martin (1995) e, para uma síntese, o capítulo 3 de David Romer (1996).

2. Para resenhas recentes dos achados nessa linha de pesquisas, de retornos macroeconômicos à educação, ver os trabalhos de Harmon; Oosterbeek; Walker (2000) e Sianesi; Van Reenen (2000). Para uma discussão sobre a relação entre qualidade da educação e crescimento econômico, ver Hanushek (2002b). 
educação, em meados da década passada, Psacharopoulos (1996) sustentava que os temas listados no parágrafo anterior são os que merecem mais investigação. 0 foco desse artigo recai justamente sobre a segunda linha de pesquisa da classificação de Blaug, em que a educação é uma variável dependente e não uma das variáveis explicativas do crescimento econômico. Mais precisamente, esse artigo trata de uma faceta dos aspectos econômicos dos sistemas educativos: o lado da oferta, provisão ou produção de educação. Procura-se apresentar a evolução histórica, o estado atual do debate e as perspectivas de desenvolvimento das teorias de oferta de educação, abarcando-se o período compreendido entre o início da década de 1960 e as contribuições mais recentes.

0 texto organiza-se da seguinte maneira. Primeiro, argumenta-se que as teorias tradicionais de educação (capital humano e sinalização) negligenciaram o lado da oferta da educação. $\mathrm{Na}$ seqüência, apresentam-se as vantagens e os limites da abordagem das funções de produção de educação, que foram e seguem sendo calculadas em inumeráveis experimentos empíricos, e cujo objetivo principal é apontar quais são os insumos mais importantes na determinação dos resultados ou produtos (output) do sistema educativo. Depois, argumenta-se que os artigos mais recentes sugerem três caminhos promissores para o desenvolvimento das teorias de oferta de educação: (i) incluir insumos não monetários às funções de produção, (ii) considerar aspectos institucionais e organizacionais do sistema educativo e (iii) aprimorar as técnicas econométricas de estimação das funções de produção. Discute-se mais detidamente o primeiro desses três caminhos, antes de se apresentarem as conclusões do artigo.

\section{A inadequação das teorias econômicas da educação tradicionais (capital humano e sinalização)}

Inúmeras críticas têm sido feitas à teoria do capital humano, mas resenhá-las exaustivamente não é o objetivo aqui ${ }^{3}$. Para os pro- pósitos deste artigo, a deficiência mais relevante da teoria do capital humano é a do descaso no tratamento dado à oferta da educação, deficiência apontada por diversos economistas da educação, como Blaug (1992) e Vandenberghe (1996). Preocupado essencialmente com os determinantes e obstáculos à demanda privada por educação, esse programa de pesquisa deu pouca atenção a possíveis restrições e empecilhos à oferta de educação, tais como: restrições infra-estruturais, tecnológicas, organizacionais ou institucionais, problemas de coordenação, problemas de motivação etc. Acreditava-se que a demanda por educação seria transformada 'automaticamente' em capital humano desde que se atenuassem as restrições de crédito.

A teoria do capital humano via as escolas como firmas especializadas na produção de educação e o sistema educativo como uma indústria que apresentava algumas peculiaridades, entre as quais se destacam as seguintes: (i) não tem, necessariamente, fins lucrativos; (ii) seus objetivos podem ser os mais variados possíveis e, geralmente, são múltiplos (instrução cognitiva e moral dos indivíduos, produção de pesquisa, divulgação de conhecimento, formação de professores, capacitação de mão-deobra etc.); (iii) seus ativos não são negociados em bolsas de valores; (iv) os consumidores estudantes ou suas famílias - não arcam com todos os custos de aquisição do bem ou serviço educação (Schultz, 1963; Johnes, 1993).

Dentro dessa perspectiva, surgiria espaço para se indagar o quão eficiente era um sistema educativo em termos de alocação de recursos - ou seja, de certa maneira, preocupar-se com a oferta de educação. Schultz (1963), por exemplo, esboça alguns exemplos de como seria possível promover aumento da eficiência das escolas: (i) redução das férias de verão - legado de uma época de costumes rurais em que longas férias eram necessárias em razão de dificuldades de transportes e de ou-

3. Para uma crítica marxista proveniente de economistas, ver Bowles; Gintis (1975). Em Belfield (2000), encontra-se uma síntese de críticas à teoria do capital humano. 
tras naturezas -, (ii) modernização das técnicas de ensino e (iii) melhor aproveitamento do tempo dos estudantes.

Porém, a teoria do capital humano não foi muito além de meramente enunciar a possibilidade de se estudar a oferta de educação. Ao analisar a teoria do capital humano do ponto de vista metodológico, Blaug (1992) classificou, como seu cerne ou essência ('hard core'), a discussão sobre os determinantes da demanda privada por educação e seus obstáculos. A discussão sobre a oferta não ocupava mais do que uma posição marginal.

A teoria da sinalização ou do filtro também não se preocupou com a oferta, pois o ataque que desferiu à teoria do capital humano dirigiu-se muito mais ao lado da demanda ${ }^{4}$. A teoria da sinalização não negava uma das principais conclusões da teoria do capital humano comprovada por estudos empíricos - de que, em média, indivíduos com maior escolaridade têm maior probabilidade de receber salários mais elevados. Apenas considerava que os teóricos do capital humano haviam sido um pouco ingênuos ao suporem que os indivíduos eram mais produtivos por causa do que a escola lhes havia oferecido em termos de aprimoramento de suas habilidades - elas já existiriam, a escola simplesmente serviria como instrumento para ressaltá-las ou sinalizá-las. De qualquer maneira, embora por razões diferentes das apontadas pela teoria do capital humano, a teoria da sinalização também acreditava que agentes racionais teriam incentivos para demandar educação póscompulsória, uma vez que isso lhes permitiria aumentar seus ganhos futuros.

A argumentação dos teóricos da sinalização ou do filtro é bastante engenhosa e certamente fornece um enfoque complementar ao da teoria do capital humano no que se refere às motivações subjacentes à demanda por educação, mas deixa a desejar no tocante à oferta de educação. Tudo o que essa linha de pesquisa tinha a dizer era que o sistema educativo não é mais do que um sinalizador para o mercado de trabalho, cumprindo a função de lhe indicar quem são os indivíduos potencialmente mais produtivos, segundo suas habilidades e seus talentos inatos. De acordo com a formulação mais extrema dessa teoria, o sistema educativo não agrega conhecimentos nem incrementa a produtividade dos indivíduos. Levando o argumento às últimas conseqüências, poder-se-ia concluir que o sistema educativo é uma mera indústria de diplomas, de 'certificação de potencial produtivo', sendo um mecanismo muito caro de triagem. Se isso fosse verdade, seria possivel conceber alternativas socialmente menos custosas e possivelmente tão eficientes quanto o sistema educativo. Um exemplo seria organizar uma bateria de testes sucessivos para ordenar as pessoas segundo seu potencial produtivo.

Portanto, nem os teóricos do capital humano nem os da sinalização estudaram atentamente a oferta de educação, que era considerada neutra ou exógena - uma espécie de 'caixa-preta'. Debates sobre os parâmetros da oferta de educação seriam assunto restrito ao âmbito de pedagogos e educadores, sobre os quais o melhor que os economistas poderiam fazer era guardar uma boa distância.

No entanto, uma vez que a educação passou a ser objeto de estudo da teoria econômica, seria natural, de um ponto de vista lógico, que mais cedo ou mais tarde se tentasse conciliar, à abordagem da demanda por educação, uma análise mais aprofundada da oferta de educação. Afinal, apesar das suas peculiaridades, a educação não deixa de ser um bem econômico, isto é, um bem escasso, cuja produção depende de escolhas (e renúncias) feitas por indivíduos e pela sociedade em termos de recursos.

Além da motivação teórica, um importante fator empírico parece ter estimulado as pesquisas do lado da oferta de educação: o aumento da parcela do PIB dos EUA gasta com educação, acompanhado de queda nos resultados em exames de avaliação de desempenho. Tal fenômeno tem sido uma constante ao lon-

4. Ver Arrow (1973), Spence (1974) e Stiglitz (1974) para os modelos originais. Ver também qualquer livro-texto de microeconomia avançada. 
go da segunda metade do século XX naquele pais (Hanushek, 2002b; Vandenberghe, 1999). Esse aumento de custos foi ainda mais grave dado o contexto fiscal e orçamentário mais restrito enfrentado pelos EUA e por outros países avançados após o fim dos chamados ‘Anos Dourados do Capitalismo' (1945-1972).

\section{Funções de produção de educação: insumos monetários e a tecnologia de produção de educação}

A solução teórica que se encontrou para incorporar o lado da oferta da educação à análise econômica foi o uso de funções de produção de educação. A idéia foi comparar as entidades do sistema escolar - escolas, faculdades, universidades etc. - a firmas que deveriam alocar seus recursos de maneira ótima, tendo em vista a tecnologia disponivel, a fim de atingir seus objetivos. Os princípios e ferramentas da microeconomia da firma foram mobilizados no intuito de avaliar, por exemplo, o nível de eficiência alocativa de determinada escola, conjunto de escolas ou, de modo agregado, de sistemas educativos.

Para isso, bastava criar modelos que considerassem os custos dos insumos (salários e condições de trabalho de professores e funcionários administrativos da escola, número de alunos por sala de aula, disponibilidade de infra-estrutura escolar, nível de educação do aluno no período anterior etc.) e que avaliassem o valor do produto final, ou seja, o nível de educação ou de pesquisa ou os resultados pós-escolares dos alunos (salários). Seria possível determinar, desse modo, a tecnologia de produção de educação à disposição das escolas. Se os modelos fossem bem concebidos, acreditava-se ser possivel encontrar a fronteira de possibilidades de produção de educação e, a partir daí, não somente conhecer quais escolas se encontravam mais ou menos distantes da fronteira (i.e. mais ou menos eficientes do ponto de vista alocativo), como também dese- nhar politicas que estabelecessem as combinações desejáveis de cada insumo para elevar o nivel de produto final.

Desde o final da década de 1960, inúmeros estudos empíricos têm sido realizados mundo afora tendo por objetivo encontrar a forma exata da tecnologia de produção de educação. Uma primeira dificuldade com que se depararam os pesquisadores que lidavam com funções de produção consistia em determinar qual era o objetivo de uma escola ou, de modo agregado, de um sistema educativo. Trata-se de maximizar o desempenho médio dos alunos? $\mathrm{Ou}$ de maximizar os conhecimentos acumulados no processo educativo ('valor agregado')? Ou minimizar a dispersão de desempenho entre alunos, seja individualmente, seja entre grupos de alunos (brancos e negros, homens e mulheres, ricos e pobres etc.)? Ou será que o objetivo é garantir que cada aluno atinja um nível mínimo de competências? Ou ainda que os alunos de maior destaque encontrem as condições para que tenham um desempenho excepcional? Sob uma ótica ainda mais ampla, o objetivo do sistema é apenas prover os alunos de certas capacidades cognitivas gerais ou prover-lhes competências e habilidades requeridas pelo mercado de trabalho? Sem estabelecer o objetivo, não seria possível aplicar as ferramentas da teoria microeconômica. Em geral, por simplicidade, os estudos optavam por considerar que o objetivo das escolas e do sistema fosse o de alcançar o mais alto nível agregado de resultados escolares dos alunos (Belfield, 2000), o que evidentemente se trata de uma escolha normativa questionável.

Definido o lado esquerdo da equação dos estudos empíricos, isto é, a variável dependente - o produto do sistema (output) - , cabia agora determinar as variáveis explicativas, ou seja, o lado direito da equação - recursos (inputs). Uma hipótese desses estudos era a de que, sendo o processo educativo semelhante à produção de outros bens, um aumento dos recursos injetados na produção (insumos) deveria conduzir a um aumento do produto (output). 
Embora à primeira vista a existência dessa relação direta entre quantidade de insumos e quantidade de produto pareça óbvia a um economista, na realidade se trata de um dos maiores debates existentes em economia da educação. Apesar do acúmulo de evidências empíricas e das centenas de artigos e livros publicados sobre o assunto desde o final da década de 1960, não se conseguiu chegar a um consenso e o debate alimenta controvérsias até hoje.

\section{Relação entre insumos monetários e output educativo: um debate de quase quatro décadas}

Em meados da década de 1960, o Departamento de Educação, Saúde e Bem-Estar dos Estados Unidos encomendou a um grupo de pesquisadores um estudo que resultou na publicação de um relatório intitulado Equality of Educational Opportunity (Coleman et al., 1966), mais conhecido como Relatório Coleman. 0 resultado mais surpreendente desse documento foi a constatação de que o desempenho escolar dependia muito mais da origem socioeconômica do aluno e do contexto escolar em que ele se encontrava do que de variáveis que representassem recursos injetados na produção de educação estas últimas, com muita freqüência, não eram estatisticamente significativas (Hanushek, 1986; Vandenberghe, 1996). Uma implicação desse estudo é que, se os recursos educativos não são tão importante na determinação de resultados, não vale a pena elevar ainda mais o nivel de gastos com esses recursos (por exemplo, aumentar os salários de professores ou reduzir a razão entre o número de alunos e o número de professores etc.), mas sim buscar outras maneiras de melhorar o desempenho dos alunos.

Após a publicação desse relatório, inúmeros outros estudos foram realizados, sobretudo nos Estados Unidos, e as interpretações das evidências são controvertidas. Naquele que é provavelmente o artigo mais citado em economia da educação nas últimas duas décadas,
Hanushek (1986) apresenta um balanço das pesquisas, por meio de uma meta-análise ${ }^{5}$ que intencionava ser exaustiva, das evidências acumuladas nos estudos de funções de produção de educação. Ele analisou 147 funções de produção contidas em diversos artigos empíricos que atendessem a certos critérios mínimos de qualidade como, por exemplo, a exigência de que tivessem sido publicados em revistas acadêmicas que contassem com pareceristas. A conclusão de Hanushek é semelhante à de Coleman em um aspecto: a maioria dos estudos mostra que a origem socioeconômica é mais importante do que os recursos ou insumos monetários. No entanto, ele é menos pessimista no que se refere ao papel da escola: ele detectou que algumas escolas e alguns professores em particular têm papel importante no aumento do desempenho escolar de seus alunos. A dificuldade seria identificar os atributos que fazem com que essas escolas e esses professores sejam mais eficazes do que outros ${ }^{6}$. Porém, a principal conclusão de Hanushek é que não existe uma relação direta entre dispêndios em recursos educativos e desempenho dos alunos.

0 artigo de Hanushek suscitou diversas críticas, sobretudo de natureza metodológica. Ao publicarem um artigo sobre o assunto alguns anos mais tarde, Card; Krueger (1992) tentaram refutar as conclusões de ausência de 'efeito-recursos' que haviam sido encontradas por Hanushek. Nesse trabalho, procurou-se aperfeiçoar o tratamento econométrico a fim de evitar erros de estimação encontrados em estudos anteriores. Incluíram-se controles para diferenças sistemáticas entre taxas de retorno à educação segundo os estados norte-americanos onde nasceram e onde viviam os indivíduos e considerou-se também a época de nascimento dos indivíduos (efeito coorte). Utilizaram-se dados transversais de diversos estados e estimaram-se salários (variável dependente) em fun-

5. Classifica-se 0 artigo de Hanushek (1986) como uma meta-análise porque não contém um estudo próprio de funções de produção, mas sim um censo dos resultados de outros estudos.

6. A esse respeito, ver a 'primeira nuança', mais adiante neste artigo. 
ção de gastos por aluno em cada estado (variável explicativa), encontrando-se coeficientes positivos e estatisticamente significativos.

No entanto, diversas críticas metodológicas se dirigiram também contra o estudo de Card; Krueger, sobretudo a de que teriam usado dados demasiadamente agregados, gerando vieses que tenderiam a superestimar os coeficientes. De fato, tentativas de replicar seus estudos em níveis mais desagregados teriam falhado (Vandenberghe, 1999; Belfield, 2000). Foram criticados também por não terem incluído nenhum controle para a origem socioeconômica dos indivíduos (Hanushek, 2002a). Por fim, no que diz respeito à variável dependente privilegiada, Card e Krueger trabalharam com resultados pós-escolares (salários) e não com resultados escolares (desempenho dos alunos em exames padronizados), como Coleman et al. (1966) e Hanushek haviam feito. Os resultados de Card e Krueger, portanto, não são estritamente comparáveis aos obtidos por seus predecessores.

Mais de uma década depois, Hanushek (1997) atualizou as evidências empíricas de seu artigo de 1986, incluindo resultados de estudos mais recentes, sem alterar o critério de considerar somente artigos publicados em revistas com parecerista, mas acrescentando o critério de apenas considerar estimações que incluíssem algum tipo de controle para a origem socioeconômica. No total, ele compilou resultados obtidos em 89 publicações anteriores a 1995, contendo em seu conjunto 376 estimações de funções de produção ${ }^{7}$.

Dessa segunda meta-análise de Hanushek, duas características saltam à vista. Primeiro, a predominância de coeficientes estatisticamente não significativos para os insumos testados, quais sejam: razão professor-aluno, escolaridade dos professores, experiência dos professores, salários dos professores, gastos por aluno, qualidade da infra-estrutura da escola, qualidade do pessoal administrativo da escola, resultados de professores em testes de avaliação. Segundo, embora a maioria dos coeficientes estatisticamente significativos apresente sinais positivos, a proporção de coeficientes com sinais negativos não é desprezível, chegando a representar metade dos coeficientes significativos para um dos insumos monetários: a razão professor-aluno. As conclusões de seu estudo de 1997 não diferem muito das de 1986: as funções de produção estimadas não dão crédito à visão de que os insumos monetários possam causar impacto substancial sobre o desempenho acadêmico dos alunos.

As respostas a Hanushek procuram criticar a metodologia utilizada em boa parte dos estudos empíricos. Dewey; Husted; Kenny (2000) propõem uma meta-análise mais ampla do que a feita por Hanushek em 1986, dividindo os estudos econométricos em 'bons' e 'ruins', representando respectivamente estudos com especificações corretas e incorretas. Concluem que a maioria (dois terços) dos coeficientes dos estudos ‘bons' são positivos e significativos - constatação claramente em contradição com a de Hanushek. Uma característica dos estudos 'ruins', segundo a classificação de Dewey et al., é incluir a renda dos pais como variável explicativa na função de produção, procedimento que, segundo eles, cria sérios problemas estatísticos que impedem que se chegue à conclusão de que os insumos educativos são importantes. Concretamente, em regressões de mínimos quadrados ordinários, haveria correlação entre as medidas de insumos escolares e o termo de erro, em razão da omissão da variável 'tempo passado pelos pais com o aluno'. A solução proposta para estudos futuros é estimar modelos com variáveis instrumentais, que possam contornar o problema de identificação.

Belfield (2000) aponta uma série de razões metodológicas que explicariam porque não se encontra uma relação entre insumos e produto em educação. Em primeiro lugar, conceitualmente pode estar errado utilizar funções de produção tradicionais no caso da educação, porque se trata de uma tecnologia em que o próprio consumidor é um insumo (via esforço do aluno ${ }^{8}$ ) e em que é difícil separar efeitos endógenos de efeitos de

7. Ver Hanushek (1997) para a compilação original e Hanushek (2002a) para uma versão revisada.

8. 0 insumo 'esforço do aluno' é abordado mais adiante neste artigo. 
contexto. Em segundo lugar, o volume de recursos educativos pode não ser um vetor de variáveis explicativas satisfatório para boas estimações, por não apresentar variação suficiente de escola para escola dentro de um mesmo país. Em terceiro lugar, estabelecimentos com menos recursos podem usá-los mais eficientemente do que estabelecimentos com mais recursos, tornando menos claro o efeito dos insumos sobre o produto. Em quarto lugar, outras variáveis relevantes podem não se manter constantes, isto é, a cláusula ceteris paribus pode não ser válida. Por exemplo, algumas escolas podem oferecer reforço a alunos em dificuldades, alocando-os em classes menores (ou seja, oferecendo-lhes mais recursos), o que pode distorcer a estimação do coeficiente associado ao efeito do tamanho de classes sobre o desempenho escolar ou do coeficiente associado ao efeito da razão aluno/professor.

Ciente das críticas metodológicas a muitos dos estudos que, em seu conjunto, detectam ausência de efeito dos recursos sobre o produto, Hanushek (2002a) reage com criticas às metodologias alternativas propostas por diversos autores, as quais, segundo ele, conduzem a resultados inconsistentes, muito sensíveis a alterações sutis na especificação do modelo e na estratégia de estimação.

Wössman (2001) endossa a posição de Hanushek ao resenhar uma série de estudos econométricos, que incluem não apenas as evidências controversas de estudos transversais com dados nacionais de alguns países (within-country cross-sections), como também de estudos mais sofisticados do ponto de vista econométrico, que se preocupam em se precaver contra a potencial endogeneidade de certos recursos no processo educativo, por intermédio da inclusão de variáveis instrumentais ou pelo uso de dados coletados em experimentos controlados ou 'naturais'. A falta de relação entre insumos e produto também se verifica, segundo o autor, em evidências provenientes de comparações internacionais e de séries de tempo nacionais. Sua conclusão é uma reafirmação daquilo que Hanushek vem dizendo há muitos anos: que não há uma relação mecânica entre recursos escolares e desempenho de alunos, ao menos nos países avançados. Afirma também que, embora haja exceções, as evidências sugerem que boa parte das escolas não é economicamente eficiente na transformação de recursos em produto, o que constitui um argumento contra o aumento do volume de recursos destinados ao sistema educativo.

Nota-se que o debate iniciado após o controvertido Relatório Coleman, em 1966, segue a pleno vapor atualmente e não se chegou a um consenso sobre a existência de uma relação entre insumos monetários e produto do sistema educativo.

\section{Primeira nuança: o 'efeito mestre'}

Hanushek (2002a) argumenta que o nível de educação dos professores em geral não é um insumo com impacto extremamente relevante sobre a atuação de alunos: em $86 \%$ das estimações, os coeficientes encontrados não são estatisticamente significativos; em 5\% delas, são estatisticamente significativos, mas negativos; em apenas 9\% delas, são estatisticamente significativos e positivos. Os coeficientes relativos à experiência dos professores são significativos e positivos em apenas um terço dos casos; na maioria dos estudos, são não significativos ou significativos e negativos. No que se refere aos resultados de professores em testes de avaliação, novamente, na maioria dos estudos, predominam os coeficientes estatisticamente não significativos (53\%). Porém, os coeficientes positivos e significativos representam 37\% do total, a porcentagem mais alta entre todos os insumos analisados. Ainda assim, trata-se de uma parcela relativamente baixa e inconclusiva, especialmente tendo em vista a pouca quantidade de estudos que mensuraram esse tipo de insumo.

À primeira vista, esses resultados podem nos levar a pensar que os professores não têm grande importância na determinação dos resultados escolares dos alunos. Contudo, certas evidências recolhidas por economistas da educação em vários estudos sugerem que a quali- 
dade dos professores é importante (Hanushek, 2002a; Vignoles et al., 2000). Trata-se, porém, da qualidade dos professores mensurada ex post - por resultados em exames de desempenho de alunos - e não da qualidade mensurada ex ante, por critérios objetivos de insumos, como nível de educação e experiência de professores. Hanushek (2002a) afirma que a magnitude da diferença de desempenho entre alunos que têm bons professores e alunos que têm maus professores (ceteris paribus) é enorme. Segundo ele, em um mesmo distrito norteamericano, em um ano letivo, os alunos de bons professores podem aprender o equivalente ao conteúdo de um ano letivo e meio, enquanto alunos de maus professores podem aprender o equivalente ao conteúdo de apenas meio ano letivo. Por fim, ele ressalta que, dado o caráter cumulativo do processo educativo, pode-se imaginar o contraste de desempenho final de um aluno que tenha tido bons professores e de outro que tenha tido maus professores ao longo de vários anos.

Essa visão é contestada por outros autores, como Pritchett; Filmer (1999), que chegam a conclusões diametralmente opostas, defendendo a posição de que outros insumos (investimento em equipamentos, por exemplo) têm retornos maiores do que o insumo "professores', e que há uma tendência à sobre-utilização deste último, em razão, por exemplo, da atuação de sindicatos fortes.

Porém, mesmo que muitos tomem partido dos estudos que defendem a importância da qualidade dos professores, poucos economistas se deram ao trabalho de investigar mais a fundo quais são os atributos que fazem de alguém um bom professor. 0 'efeito mestre' ainda é uma caixa-preta. Resta saber até que ponto se trata de atributos pessoais dificilmente transferiveis (carisma, por exemplo) e até que ponto podem ser incorporados pelos diferentes professores (via treinamento adequado, por exemplo). Se forem transferiveis, poderão ser considerados como insumos monetários, por serem, ao menos em teoria, passíveis de serem adquiridos no mercado - o governo pode pagar o treinamento de um grupo de professores, por exemplo. Caso contrário, deverão ser considerados como insumos não monetários.

\section{Segunda nuança: evidências de países em desenvolvimento}

A maioria dos artigos discutidos nesta seção, tanto os de Hanushek e aqueles que estão de acordo com ele como pelos seus 'adversários' no debate, baseia-se essencialmente em evidências colhidas em países avançados, sobretudo nos Estados Unidos. Esses artigos freqüentemente incluem breves comentários, em geral relegados a seções curtas ou a notas de rodapé, a respeito de funções de produção nos paises em desenvolvimento.

Uma explicação dada pelos autores para esse tratamento apenas marginal conferido aos países em desenvolvimento é a ausência de um conjunto suficientemente vasto de estudos 'de qualidade' (isto é, publicados em revistas acadêmicas internacionais) sobre esses países. Sempre se adverte, no entanto, que é importante observar as evidências provenientes de países em desenvolvimento, porque as escolas nestes funcionam, em média, com quantidades de recursos muito inferiores às de que dispõem as escolas dos países avançados. É, portanto, uma forma de aumentar a variabilidade de variáveis explicativas, proporcionando uma melhoria potencial da qualidade da estimação. Além disso, esses estudos podem servir para testar a hipótese de que as escolas dos países avançados já estejam operando em uma zona de retornos decrescentes, enquanto as de países em desenvolvimento estariam operando ainda em uma zona de retornos crescentes. Por exemplo, reduzir o número de alunos por classe de trinta para vinte e cinco pode não surtir maiores efeitos, porém, reduzir de sessenta para quarenta poderia fazer uma diferença considerável.

A mensagem das breves referências aos resultados de estimações de funções de produção em países em desenvolvimento costuma ser 
a de que a relação entre insumos e produtos nos sistemas educativos desses paises parece ser um pouco mais forte do que nos paises desenvolvidos (Jarousse, 1991; Wössman, 2001; entre outros). Hanushek (2002a) ressalta, porém, que as evidências não são conclusivas, o que não autoriza a inferência de que políticas de expansão de recursos sejam recomendáveis aos países em desenvolvimento em quaisquer circunstâncias.

Quanto à realidade brasileira, não é possivel afirmar nada sem analisar estatisticamente os dados de recursos e de resultados em exames de desempenho, ou seja, sem reproduzir as estimações de funções de produção tais como as que foram realizadas nos países avançados. Barros et al. (2001) fizeram estudo em que procuram apontar os determinantes do desempenho educacional no Brasil, com base em dados provenientes da Pesquisa Nacional por Amostragem de Domicílios - PNAD - e da Pesquisa sobre Padrões de Vida - PPV - , ambas realidas pelo Instituto Brasileiro de Geografia e Estatística - IBGE. A variável dependente é a escolaridade (número de séries completadas pelo indivíduo), em vez de resultados em exames de desempenho, como Hanushek, ou resultados pós-escolares (salários), como Card; Krueger. De início, alertam sobre a falta de estudos desse tipo no país, especialmente de trabalhos que avaliem a importância dos recursos educativos (que denominam 'qualidade dos serviços educacionais'): "no que se refere à qualidade dos serviços educacionais e dos recursos comunitários sobre o desempenho educacional, [apenas] algumas estimativas esparsas podem ser obtidas" (Barros et al., 2001, p. 2). Seus resultados mostram que certos insumos monetários (mas não todos), sobretudo a disponibilidade de equipamentos, têm influência sobre o desempenho dos alunos do ensino fundamental (mas não sobre o ensino médio) e também que o efeito da origem socioeconômica é decisivo. Sem desprezar a evidência encontrada de que os insumos monetários têm certa importância, pode-se interpretar que, de certa forma, esses resultados reproduzem os principais elementos do debate internacional: resultados contraditórios quanto ao efeito dos insumos monetários, mas incontestáveis quanto ao impacto exercido pela origem socioeconômica.

Antes de afirmar quais políticas são mais recomendáveis, seria importante comparar esse estudo com outros realizados no Brasil. Essa precaução deve ser tomada para se evitar a armadilha de se tirarem conclusões com base em evidências particulares, pois, como se viu nesta seção, os resultados dos diferentes estudos nos países avançados muitas vezes são opostos, em função do uso de diferentes bases de dados ou de diferentes metodologias de estimação.

\section{Insuficiências da abordagem da função de produção e as alternativas}

Embora tenham representado um avanço com relação aos trabalhos que só se preocupavam com a demanda por educação, os modelos de funções de produção mais simples, que consideravam apenas os insumos monetários, padeciam de alguns males. Por um lado, eram representações extremamente simplificadas e mecanicistas do processo educativo. Por outro lado, os estudos empíricos neles baseados não foram capazes de revelar nitidamente quais eram os insumos verdadeiramente importantes, como visto no debate cuja evolução foi narrada nas seções anteriores. A influência decisiva da origem socioeconômica do indivíduo sobre o resultado escolar parece ser uma das poucas certezas que se têm. Além disso, tentativas de replicar casos bem-sucedidos de projetos educativos de determinadas escolas em outras localidades não costumavam dar certo. A mesma dificuldade era enfrentada quando se tentavam expandir projetos pilotos para territórios mais amplos (Vandenberghe, 1999). A busca pelos parâmetros da tecnologia de produção de educação parecia estar fadada ao insucesso.

Inúmeros artigos recentes têm defendido a necessidade de se buscarem alternativas ${ }^{9}$. Para 
Vandenberghe (1999), por exemplo, um caminho promissor consiste em incorporar efeitos de pares e características organizacionais às funções de produção tradicionais. Bishop; Wössman (2001) propõem um modelo de produção de educação que integre evidências recentes de que o desempenho dos alunos é afetado por diversas 'instituições' - existência de exames centrais, grau de autonomia decisória das escolas, grau de influência dos professores e pais nas decisões escolares, existência ou não de concorrência entre escolas etc. Belfield (2000), por sua vez, propõe arcabouços de análise diferentes, como; (i) descrever a estrutura, a conduta e o desempenho de instituições educativas, (ii) estudar características institucionais que fazem certas escolas serem mais efetivas e (iii) investigar, por meio de estudos de caso, de que forma as instituições educativas respondem a novas circunstâncias.

No meu modo de entender, esses artigos recentes permitem vislumbrar três caminhos promissores a serem trilhados e que, na realidade, não são mutuamente excludentes, mas sim complementares, em certa medida. São eles:

- Ampliar as funções de produção, incorporando-lhes novos insumos, não exclusivamente monetários como visto até aqui, mas também os insumos não monetários ou extramercado;

- Ir além das funções de produção simples e tentar compreender o papel da estrutura de incentivos, das instituições e de características organizacionais dos sistemas educativos, isto é, considerar os custos de transação e não apenas os de produção;

- Aprimorar as técnicas econométricas aplicadas às estimativas de funções de produção de educação a fim de refinar a distinção entre estudos bem ou mal especificados já realizados e guiar o trabalho empírico futuro.

Na impossibilidade de discutir cada um desses três caminhos neste artigo, optou-se por privilegiar o primeiro deles: a inclusão de insumos monetários às funções de produção. Antes de passar a essa discussão, cabem alguns breves comentários a respeito dos outros dois caminhos.

Com relação ao segundo caminho, a literatura ainda se encontra em estágio embrionário. Os enfoques são variados, mas os ingredientes básicos dos modelos teóricos são os seguintes: (i) uso de pressupostos comportamentais e informacionais heterodoxos: comportamento oportunista, capacidade cognitiva limitada, incerteza, existência de custos de transação etc.; (ii) consideração de aspectos organizacionais de escolas e de sistemas educativos - relações de agência, problemas de coordenação intra e interescolas, problemas de 'ineficiência-x' -, os quais, no processo educacional, fazem com que a relação entre insumos e produtos não seja tão mecânica como previam os modelos de função de produção; e (iii) incorporação de variáveis representando instituições informais (rumores, reputações, estruturas de incentivo espontâneas etc.) e formais (grau de autonomia das escolas, existência ou não de mecanismos de certificação oficial, de exames centrais padronizados, de penas e recompensas, a influência de diferentes estruturas de governança etc.), que surgem ou são criadas para reduzir custos de transação e que têm efeitos sobre o output escolar. Invariavelmente, tais estudos baseiam-se em distintas vertentes da nova economia institucional.

No que se refere ao terceiro caminho aprimoramento das técnicas econométricas de estimação das funções de produção -, trata-se de seguir na mesma trilha das funções de produção tradicionais, mas incorporando técnicas econométricas mais recentes e sofisticadas. É preciso ter em mente que mensurar a contribuição de cada insumo à produção de educação não é tarefa simples. Ao se tentar avaliar o nível de conhecimentos ou a capacidade cognitiva de um indivíduo em determinada etapa do proces-

9. Entre os artigos que sugerem alternativas, destacam-se: Vandenberghe (1999), Akerlof; Kranton (2002), Bishop; Wössman (2001), Hanushek (2002a; 2002b). Há também uma vasta literatura de 'econometria da educação', que procura encontrar soluções para problemas de especificação nas funções de produção de educação. Boas referências sobre esse assunto são Dewey; Husted; Kenny (2000) e Vignoles et al. (2000). 
so educativo, não é fácil distinguir, em uma regressão, que parcela de seu desempenho se deve a características inatas, o quanto se deve a conhecimentos e habilidades adquiridos em função do esforço da escola (insumos essencialmente monetários), qual é a porção dos conhecimentos e habilidades que foram adquiridos por causa do esforço do próprio aluno ou em razão da 'qualidade' do grupo de colegas (efeito de pares), da dedicação ou disponibilidade dos pais em casa (capital social familiar) ou de um ambiente comunitário favorável (capital social comunitário). Há ainda outras peculiaridades do processo educativo que dificultam o trabalho do econometrista da educação. Um exemplo: o processo é cumulativo. Outro exemplo: pode haver dependência de escolhas a serem tomadas no periodo corrente com relação as realizadas anteriormente. Enfim, uma série de precauções tem de ser observada na realização de estudos empíricos em economia da educação.

\section{Os insumos não monetários}

Nesta seção, discute-se mais detidamente o primeiro caminho, apontado como promissor para o desenvolvimento futuro das teorias de oferta de educação. Trata-se de incluir insumos não monetários às funções de produção. 0 objetivo desta seção é clarificar um pouco mais o que se entende por insumos não monetários no contexto educacional e sob um ponto de vista econômico. Ressalte-se que a literatura econômica disponível nesse campo ainda é muito restrita.

Ao contrário dos insumos monetários, os insumos não monetários ou insumos extramercado não podem ser 'comprados' no mercado. Os esforços dos alunos, os efeitos de pares e o capital social, entendido como o papel da família e da comunidade na produção de educação, têm sido apontados como os mais relevantes no contexto educacional.

Em termos concretos, o gestor da educação pode decidir utilizar mais recursos a fim de pagar salários mais altos aos professores, de reduzir a razão alunos/professor por sala de aula ou de comprar mais equipamentos para as escolas, mas dificilmente poderá destinar mais recursos visando a fazer com que os pais se envolvam mais com os filhos, a proporcionar, a um dado aluno, colegas mais motivados pelos estudos e mais bem disciplinados ou a prover-lhe um ambiente comunitário favorável aos estudos.

\section{Esforços dos alunos como insumos educativos}

Diversos economistas da educação chamam a atenção para uma peculiaridade da educação, que a distingue de outros bens: o fato de que o próprio consumidor é um insumo de produção. 0 desempenho do aluno ao final de um processo educativo depende da sua dotação de competências cognitivas (de capital humano) no início do processo, bem como do esforço realizado pelo aluno durante o processo de educação, seja na escola, seja em casa (Belfield, 2000). Alguns autores suspeitam mesmo que o esforço dos alunos seja o insumo mais importante no processo educacional, ao menos em termos de alocação de tempo. Seu raciocínio é o seguinte: dada uma razão de alunos por professor de 20 para 1, por exemplo, o conjunto dos alunos passará 20 vezes mais tempo estudando do que os professores ensinando (Bishop; Wössman, 2001).

Contudo, mesmo reconhecendo a importância do esforço dos alunos, os economistas não estudaram a fundo os determinantes do esforço. Ainda está muito carente de desenvolvimentos a "microeconomia da sala de aula" (Belfield, 2000) e são poucos os artigos que procuram estabelecer uma ligação entre outras ciências preocupadas com a educação e a teoria econômica. Ainda há espaço para muitos desenvolvimentos nessa área.

Um artigo bastante recente, de Akerlof; Kranton (2002), é um dos poucos a tratar do assunto. Seus autores constataram que as motivações atribuídas às crianças e aos adolescentes na escola pela literatura de sociologia, psicologia 
e história da educação são bastante diferentes das que lhes são atribuídas pelos economistas. A fim de conciliar essas visões conflitantes, propõem um modelo nos moldes habituais da teoria econômica, mas que incorpora elementos usualmente ignorados pelos economistas. Nesse modelo, os alunos procuram maximizar não apenas o valor presente do retorno pecuniário a seus estudos, como também - e principalmente - integrar-se a certas categorias sociais existentes na escola. A função utilidade de alunos inclui como atributos, portanto, elementos sociopsicológicos, como identidade ou auto-imagem.

A literatura não econômica mostra que os alunos dividem-se em categorias sociais nas escolas e que procuram se integrar (to fit in) a alguma delas. Os autores incluem quatro categorias em seu modelo: 'estudiosos', 'esportistas', 'populares' ou 'líderes' e 'casos perdidos' ${ }^{10}$. A cada uma dessas categorias, associa-se um modelo (ideal type) de atributos físicos e de comportamento. Os alunos maximizam a utilidade como resultado de duas escolhas: da categoria social a que desejam pertencer (o que depende da distância entre suas características e as do modelo prescrito por cada categoria social) e do esforço que fazem na escola. A escolha da categoria social tem influência sobre o esforço que fazem, pois a imagem e a autoimagem do estudante dependem da adequação entre seu comportamento e aquele prescrito pela categoria social que escolheram. Um indivíduo que pertence à categoria dos 'estudiosos', por exemplo, tem mais estímulos - em termos de integração social - a fazer esforços do que um indivíduo que se encaixa na categoria 'casos perdidos'. Os autores citam evidências de que,

[...] em escolas onde o desempenho acadêmico não era um critério para alguém fazer parte do grupo de 'populares' ou 'lideres' (leading crowd), alunos com alto Q1 reduziam seu desempenho; os melhores alunos tinham baixa probabilidade de serem aqueles com Q1 mais alto. (Akerlof; Kranton, 2002)

Segundo esse modelo, portanto, a interação social tem efeitos sobre os esforços dos alu- nos e, por conseguinte, sobre os resultados escolares. Uma implicação importante em termos de políticas é que a eficácia na aquisição de qualificações não responderá tanto a mudanças nos salários, nos custos dos estudos ou nos insumos monetários postos à disposição da escola, mas sim em termos de parâmetros sociais. As políticas educacionais deverão, portanto, considerar parâmetros tais como o grau de dificuldade do aluno para se identificar e se integrar com os outros alunos. Além disso, será preciso conhecer bem as categorias sociais de cada escola ou grupo de escolas, bem como seus efeitos sobre o desempenho escolar dos alunos. Embora isso seja óbvio a não-economistas estudiosos da educação, é preciso reconhecer o mérito do modelo de Akerlof e Kranton, qual seja, o de traduzir essas preocupações e implicações para a linguagem e a modelagem padrão com que o economista trabalha.

Por outro lado, é possivel complementar a abordagem pioneira desses autores com a introdução do conceito de 'efeito de pares', o que se faz na seçào seguinte. Por outro lado, seguindo a mesma linha de raciocínio, é possível generalizar a idéia de que as interações sociais são importantes não apenas na escola, como querem Akerlof e Kranton, mas sim em diversos outros ambientes sociais que influenciam os alunos, especialmente a família e a comunidade, resumidos pelo termo "capital social'"1.

\section{Efeitos de pares: o papel dos colegas}

0 conceito de direitos de propriedade é útil para abordar os efeitos de pares. Direitos de propriedade representam o alcance da capacidade de extração de benefícios de um ativo econômico pelos agentes. Um agente pode extrair benefícios de determinado ativo (i) por meio de seu uso, (ii) por meio de um contrato com outro indivíduo (aluguel, por exemplo) ou (iii) via transferência permanente do ativo a

10. Tradução livre das seguintes categorias, mencionadas no artigo de Akerlof; Kranton (2002): nerds, jocks, leading crowd, burnouts.

11. 0 'capital social' será discutido mais adiante neste artigo. 
outro indivíduo. Fazer cumprir os direitos de propriedade (enforcement) envolve custos, pois é necessário excluir outros indivíduos do usufruto dos benefícios do ativo de que se dispõe. Com freqüencia, o estado, ou outra terceira parte, é chamado a intervir para realizar o 'enforcement' desses direitos. Em muitos casos, porém, não é fácil definir e proteger claramente os direitos de propriedade, devido à existência de ambigüidades ou de efeitos de transbordamento (spillover effects). Um bom exemplo são bens como o ar: pertence a todos e a ninguém, pois não se podem excluir algumas pessoas do direito ao uso (Eggertson, 1990).

No caso da educação, há um exemplo importante de efeito de transbordamento: tratase do chamado 'efeito de pares' ou 'efeito contexto', denominados na nomenclatura ortodoxa de social local spillover effects. Desde o Relatório Coleman, diversos estudos têm defendido a idéia de que os conhecimentos assimilados por um aluno na escola dependem em grande medida do grupo de colegas com que ele convive, ou seja, do seu contexto social escolar ou da 'qualidade' de seus pares, em termos de comportamento ou de talento intelectual, por exemplo. Quanto 'melhores' forem os colegas de determinado aluno, mais esse aluno terá chances de aprender melhor e aumentar suas capacidades cognitivas. 0 fato de estar em uma classe com alunos mais talentosos estimula um aluno mais fraco. A situação inversa também é verdadeira: estar em companhia de colegas pouco talentosos reduz o desempenho de um aluno. As características pessoais ou o comportamento de um aluno em sala de aula têm, portanto, impacto (negativo ou positivo) sobre os outros. Pode-se dizer que os atributos dos colegas são insumos à função de produção de educação de cada aluno.

Todavia, não é possível estabelecer um contrato que estipule os termos de troca de 'efeitos de pares'. Não é possível ao aluno A pagar uma quantia para que o aluno B tenha características diferentes das que têm ou para que adote um comportamento mais adequado na sala de aula. Efeitos de pares são, portanto, bens coletivos, cujos direitos de propriedade não são bem definidos e não podem ser trocados em termos estabelecidos em um contrato. $\mathrm{Na}$ terminologia padrão da economia neoclássica, pode-se dizer que são externalidades que dificilmente poderão ser internalizadas.

Em termos econométricos, a implicação da existência de efeitos de pares é a exigência de cuidados ainda maiores na especificação dos modelos a serem estimados. Segundo Hanushek et al. (2001), variáveis omitidas e erros de medida enviesam os resultados de diversos estudos econométricos que procuraram mensurar a magnitude dos efeitos de pares sobre o desempenho dos alunos ${ }^{12}$. No Brasil, por exemplo, uma tentativa de comparação entre a eficácia de escolas públicas e privadas que não considerar os efeitos de pares envolvidos, provavelmente superestimará a eficácia da escola privada.

Em termos de política educativa, a principal implicação da existência de efeitos de pares é a importância que adquire a maneira como são distribuídos os alunos entre salas de aula e entre escolas. Dificilmente uma classe composta exclusivamente por alunos cujos pais têm nível de escolaridade baixo alcançaria os mesmos resultados médios de uma classe de alunos cujos pais são mais escolarizados, mesmo que ambas as classes contassem com os mesmos professores e a mesma infra-estrutura física. Ao se considerar o efeito de pares, presume-se que um sistema educativo socialmente segregado possa ser ainda mais perverso, do ponto de vista da distribuição de educação, do que se costuma imaginar. Por outro lado, classes heterogêneas (sem segregação) em termos de talento ou capacidade dos alunos poderiam eventualmente ser prejudiciais aos melhores alunos. Portanto, a maneira como são distribuídos tem efeitos potencialmente importantes sobre a eficácia e a eqüidade do sistema. Em certa medida, o gestor do sistema educativo pode ver-se confrontado a um dilema entre as

12. Hanushek et al. (2001) apresentam, na introdução de seu artigo, uma resenha da literatura empírica sobre efeitos de pares. 
opções de misturar ou segregar os alunos (mixing or streaming, cf. Glewwe, 1997): a escolha que tomará dependerá da magnitude das perdas e dos ganhos de alunos fracos e fortes, em cada um dos casos, e do peso atribuído a essas perdas e ganhos, isto é, da posição normativa adotada.

Ao estudar a fundo o sistema escolar belga, Vandenberghe (1996) concluiu que a forte segregação desse sistema de ensino tem efeitos negativos em termos de eqüidade. 0 efeito de pares é, segundo ele, um importante canal de transformação da segregação em diferenciais de avanço escolar e reprovação (a variável dependente de seu trabalho). No entanto, o mesmo autor ressalta que o gestor de um sistema educativo se confrontará com dois desafios ao se dar conta da existência de efeitos de pares. 0 primeiro será identificar qual é a alocação 'ideal' de alunos com vistas a maximizar objetivos sociais de eficácia e eqüidade - o que pressupõe escolhas normativas. Definida a alocação 'ideal', o segundo desafio será convencer (ou incentivar) pais e alunos a aceitarem tal alocação, que certamente implica perdas privadas para certos alunos.

Por fim, é importante ressaltar que, apesar de o reconhecimento da possibilidade de existência de efeitos de pares já ser bastante difundido, poucos economistas da educação se preocuparam em estudar mais aprofundadamente os mecanismos por meio dos quais os colegas ou pares efetivamente influenciam o desempenho dos outros colegas (Hanushek et al., 2001; Vandenberghe, 1996).

\section{Capital social: o papel da família e da comunidade}

Os efeitos de pares não se restringem ao âmbito escolar. Em diversas situações, modelar e compreender o desenvolvimento pessoal dos indivíduos requer que se considere a natureza e a qualidade das interações que tais indivíduos mantêm com o seu entourage imediato. Também se verificam efeitos de pares, ou externalidades sociais locais, nas famílias, em empresas, em bairros ou associações. Para caracterizar essa espécie de generalização da idéia de efeito de pares ou de externalidades sociais locais, alguns observadores preferem evocar o termo 'capital social'.

Segundo Coleman (1988), o conceito de capital social combina a importância da estrutura social e das relações interpessoais - idéias caras à abordagem sociológica - ao paradigma de ação racional dos indivíduos, hipótese de base da teoria econômica. Em outras palavras, tenta-se assim reconciliar a idéia de que os agentes vivem em sociedade e suas ações são governadas por normas, regras e obrigações sociais, com o pressuposto de que os indivíduos são racionais e auto-interessados, isto é, com o pressuposto do homo economicus. Coleman e outros autores (Bénabou, 1994) defendem igualmente que o capital social, no processo educativo, é importante na formação de capital humano. Mais relevante para o enfoque deste artigo é a constatação de que o capital social também pode ser considerado uma forma de insumo não monetário no processo educativo.

Determinadas estruturas sociais seriam particularmente úteis aos indivíduos na busca por seus objetivos (individuais). Entre os exemplos apresentados por Coleman, pode-se evocar o de uma mãe que se sente tranqüila em deixar seus filhos brincarem na rua do bairro onde moram, mesmo se ela não está presente, uma vez que confia em seus vizinhos, os quais têm o costume de cuidar dos filhos dos outros. Se em outra rua ou bairro isso não se verifica, o capital social dessa segunda localidade é inferior ao da primeira. Brooks-Gunn et al. (1993) mostram que, com tudo o mais constante, as características de um bairro especialmente o nível de renda de seus moradores - determinam parcialmente a freqüência de eventos como a maternidade de adolescentes e o fracasso escolar.

Coleman enumera três formas de capital social: (i) as obrigações, as expectativas e a confiança com relação aos outros; (ii) os canais de informação; e (iii) as normas e as sanções sociais. No primeiro grupo, ele inclui tudo o que se refere a mecanismos de ajuda recíproca, que funcionam sem o apoio de um quadro jurídico pró- 
prio (ou seja, sem mecanismos de enforcement). Um exemplo: os sistemas de cooperativas de crédito na Ásia ou a confiança entre vizinhos, mencionada no parágrafo anterior. A segunda forma de capital social envolve as relações sociais - mantidas para outras finalidades - por meio das quais a informação pode ser obtida a um baixo custo. Um exemplo é o de um pesquisador científico que consegue se manter atualizado em campos do conhecimento relativamente próximos ao seu por intermédio do contato com colegas implicados nessas áreas. A terceira forma constitui-se da aprovação (ou não) de certas ações. 0 exemplo é o de uma escola que enfrenta poucos problemas disciplinares devido ao fato de pertencer a um bairro que 'recompensa' o bom desempenho acadêmico. Nos três casos, os indivíduos obtêm vantagens individuais, que se manifestam em razão da existência de estruturas sociais particulares.

Em uma família, o capital social útil às crianças depende da presença (física) dos pais, da atenção dispensada por estes aos seus filhos e da infra-estrutura de estudos proporcionada. Uma estrutura familiar 'não tradicional', como as famílias monoparentais, poderia ter efeitos negativos sobre o capital social posto à disposição das crianças, mesmo em se tratando de pais com elevado nivel de capital humano. Os pais influenciam o desempenho escolar dos filhos, não apenas diretamente - por meio de ajuda em lições de casa, envolvimento em decisões tomadas na escola ou ainda na provisão de equipamentos e condições de estudo adequadas - como também indiretamente - por meio da transmissão de disciplina de estudo, normas de comportamento, atitude com relação à escola, motivação etc., sendo a participação dos pais nas atividades escolares dos filhos com freqüência uma variável positivamente correlacionada à classe social dos pais, o insumo 'capital social familiar' parece ser um dos (inúmeros) canais por meio dos quais a origem socioeconômica influencia o desempenho escolar de alunos (Vandenberghe, 1996; Belfield, 2000).

Belfield lança a hipótese de que "não apenas os insumos dos pais podem ser subs- tanciais, como também podem apresentar uma taxa de retorno marginal maior do que os insumos [injetados pelo] governo" (2000, p. 137). No entanto, o autor afirma que as evidências empíricas da importância do capital social familiar não permitem que se cheguem a resultados conclusivos, sobretudo em razão das dificuldades empíricas envolvidas.

0 capital social comunitário desempenha um papel potencialmente importante no aproveitamento escolar dos alunos. Em geral, as escolas de bairros, nos quais os pais ou os líderes comunitários são mais ativos e presentes às tomadas de decisões escolares relevantes, são dotadas de mais capital social do que as escolas em que as famílias ou comunidades permanecem distantes. No primeiro caso, é bem possivel que os alunos tenham maiores benefícios em termos de aquisição de competências cognitivas. Coleman (1988) constata, por exemplo, com base em estudos empíricos, que um forte capital social, familiar ou da comunidade de adultos cujas decisões afetam a escola, podem trazer vantagens, como reduzir a freqüência de evasão escolar.

\section{Conclusões}

Este artigo ocupou-se de uma faceta particular (o lado da oferta) de uma das duas grandes linhas de pesquisa em economia da educação (aspectos econômicos dos sistemas educacionais) e procurou apresentar a evolução histórica, o estado atual do debate e as perspectivas de desenvolvimento das teorias de oferta de educação, abarcando o período compreendido entre o início da década de 1960 e as contribuiçòes mais recentes.

Viu-se que a teoria do capital humano não foi muito além de enunciar a possibilidade de se estudar a oferta da educação, enquanto a teoria da sinalização não se preocupou em nada com esse aspecto. A oferta era, para ambas as correntes teóricas, uma espécie de 'caixa-preta' neutra ou exógena: acreditava-se que toda demanda por educação seria transformada em capital humano. 
Motivações teóricas e empíricas estimularam a preocupação com a oferta de educação, sobretudo nos EUA. Os conceitos e o instrumental da microeconomia da firma foram aplicados na estimação de inúmeras funções de produção, que tentavam encontrar a tecnologia de produção de educação. Apesar do acúmulo de evidências empíricas ao longo de mais de 40 anos de pesquisas, não foi possivel estabelecer-se um consenso a respeito da existência de uma relação direta entre insumos monetários e produto escolar. 0 debate, ainda em aberto, tem sido caracterizado, sobretudo, por disputas metodológicas acerca das técnicas econométricas empregadas e da qualidade das fontes de dados utilizadas.

Artigos recentes têm defendido a necessidade de se buscarem alternativas às estimações de funções de produção de educação mais simples. Argumentou-se que três caminhos distintos, e até certo ponto complementares, podem ser identificados como promissores: (i) ampliar as funções de produção, incorporandolhes insumos extramercado; (ii) considerar aspectos institucionais e organizacionais do sistema educativo, isto é, considerar os custos de transação e não apenas os de produção; e (iii) aprimorar as técnicas econométricas de estima- ção das funções de produção de educação.

Alguns breves comentários foram mencionados a respeito dos itens (ii) e (iii), enquanto se procurou discutir mais detidamente o item (i). 0 ponto principal a reter com relação a esse 'primeiro caminho' de desenvolvimento das teorias de oferta de educação é que, para se modelar e compreender o desenvolvimento escolar dos alunos, é preciso considerar a natureza e a qualidade de suas interações sociais, seja na sala de aula, no pátio da escola, no seio da família ou da comunidade em que vivem. Idealmente, essas preocupações deveriam ser incorporadas tanto em modelos teóricos como em futuros trabalhos empíricos que visem investigar a produção de educação.

Viu-se, porém, que os insumos não monetários ainda merecem investigações mais atentas por parte dos economistas que, em geral, limitaram-se a registrar sua importância sem estudar a fundo os mecanismos de transformação de insumos não monetários em aprendizado. De modo geral, as teorias econômicas de oferta de educação ainda apresentam questões em aberto, debates em curso, controvérsias sem respostas conclusivas. Há espaço para muitos desenvolvimentos teóricos e empíricos. Certamente, há muito trabalho pela frente ao economista da educação.

\section{Referências bibliográficas}

AKERLOF, G. A.; KRANTON, R. E. Identities and schooling: some lessons for the economics of education. Journal of Economic Literature, v. 40, n. 4, dez./2002.

ARROW, Kenneth. Higher education as a filter. Journal of Public Economics, n. 2, p. 103-216, 1973.

BARRO, R.; SALA-I-MARTIN, X. Economic growth. Nova York: McGraw-Hill, 1995.

BARR0S, R. P. et al. Uma análise dos determinantes do desempenho educacional no Brasil. Texto para discussão do IPEA, n. 834, 2001.

BELFIELD, C. R. Economic principles for education: theory and evidence. Cheltenham, Reino Unido e Northampton, MA, EUA: Edward Elgar, 2000.

BÉNABOU, R. Education, income distribution and growth: the local connection. National Bureau of Economic Research Working Paper, n. W/4798, 1994.

BISHOP, J. H.; WÖSSMAN, L. Institutional effects in a simple model of educational production. Kiel Working Paper, Kiel, Alemanha, n. 1085, nov./2001. 
BLAUG, M. The methodology of economics. 2a ed. Cambridge: Cambridge University Press, 1992.

BOWLES, S.; GINTIS, H. The problem with human capital theory: a marxian critique. American Economic Review, v. 65, n. 2, p. 74-82, maio/1975.

BROOKS-GUNN, J. et al. Do neighborhoods influence child and adolescent development? American Journal of Sociology, v. 99, n. 2, p. 353-395, set./1993.

CARD, D.; KRUEGER, A. B. Does school quality matter? Return to education and the characteristics of public schools in the United States. Journal of Political Economy, v. 100, n. 1, p. 1-40, 1992.

COLEMAN, J. S. Social capital in the creation of human capital. American Journal of Sociology, v. 94, Supplement S95-S120, 1988.

COLEMAN, J. S. et al. Equality of educational opportunity, Washington, DC: US Government Printing Office, 1966.

DEWEY, J.; HUSTED, T. A.; KENNY, L. W. The ineffectiveness of school inputs: a product of misspecification? Economics of Education Review, v. 19, n.1, p. 27-45, 2000.

EGGERTSON, T. Economic behavior and institutions, Cambridge Surveys of Economic Literature, Cambridge: Cambridge University Press, 1990.

GLEWWE, P. Estimating the impact of peer group effects on socioeconomic outcomes: does the distribution of peer group characteristics matter? Economics of Education Review, v. 16, n. 1, p. 39-43, 1997.

HANUSHEK, E. E. The economics of schooling: production and efficiency in public schools. Journal of Economic Literature, v. 24, p. $1141-1177,1986$.

Assessing the effects of school resources on student performance: an update. Educational Evaluation and Policy Analysis, v. 19, n. 2, p. 141-164. 1997. 2002a.

The failure of input-based schooling policies. National Bureau of Economic Research Working Paper, n. W/9040, 2002b.

The long run importance of schools quality. National Bureau of Economic Research Working Paper, n. W/9071,

HANUSHEK, Eric E. et al. Does the ability of peer affect student achievement? National Bureau of Economic Research Working Paper, n. W/8502, 2001.

HARMON, C.; OOSTERBEEK, H.; WALKER, I. The returns to education: a review of evidence, issues and deficiencies in the literature. Centre for the economics of education discussion paper, London School of Economics, n. 5, 2000.

JAROUSSE, J.-P. L'économie de l'éducation: du capital humain à l'évolution des processus et des systèmes éducatifs. Repères Bibliographiques, Perspectives Documentaires en Education, n. 23, p. 79-105, 1991.

JOHNES, G. Economía de la educación: capital humano, rendimiento educativo y mercado de trabajo. Tradução (inglêsespanhol) de CELER (Servicio Técnico de Traducciones). Madrid: Centro de Publicaciones, Ministerio de Trabajo y Seguridad Social, 1993.

LUCAS, R. On the mechanisms of economic development. Journal of Monetary Economics, n. 22, p. 2-42, 1988.

PRITCHETT, L.; FILMER, D. What education production function really show: a positive theory of education expenditures. Economics of Education Review, v.18, n. 2, p. 223-239, 1999.

PSACHAROPOULOS, G. Economics of education: a research agenda. Economics of Education Review, v. 15, n. 4, p. 339-344, 1996. 
RASERA, J.-B. L'économie de l'éducation et la question du développement. In: PAUL, J.-J. (Ed.) Administrer, gérer, évaluer les systèmes éducatifs: une encyclopédie pour aujourd'hui. Paris: Pédagogie outils, ESF éditions, 1999.

ROMER, D. Advanced macroeconomics. Nova York: McGraw-Hill, 1996.

ROMER, P. Endogenous technological change. Journal of Political Economy, v. 98, n. 5, p. S71-S102, 1990.

SCHULTZ, T. Economic value of education. Nova York: Columbia University Press, 1963.

SIANESI, B.; VAN REENEN, J. The returns to education: review of the macro-economic literature. Centre for the economics of education discussion paper, London School of Economics, n. 6, 2000.

SPENCE, M. Model 2: education as a signal. In: Market signalling information transfer in hiring and related screening processes, Cambridge, MA: Harvard University Press, 1974, Cap. 3.

STIGLITZ, J. The theory of 'screening': education and the distribution of income, American Economic Review, n. 65, p. 283-300, 1974.

VANDENBERGHE, V. Functioning and regulation of educational quasi-markets. 1996. Tese (Doutoramento)- Louvain-la-Neuve, Bélgica: Ciaco, 1996.

. Economics of education: the need to go beyond human capital theory and production-function analysis. Educational studies, v. 25, n. 2, p. 129-143, 1999.

VIGNOLES, A. et al. The relationship between resource allocation and pupil attainment: a review. Centre for the economics of education discussion paper, n. 2, London School of Economics, 2000.

WÖSSMAN, L. New evidence on the missing resource-performance link in education. Kiel Discussion Paper, Kiel, Alemanha, n. 1051, 2001.

Recebido em 18.02.05

Modificado em 07.09.05

Aprovado em 13.02.06

Fábio D. Waltenberg é bacharel e mestre em economia pela Universidade de São Paulo. Atualmente, é doutorando em economia e pesquisador no Departamento de Economia e no Groupe Interfacultaire de Recherche sur les Systèmes d'Education et de Formation (GIRSEF), pela Université Catholique de Louvain, na Bélgica. Sua área de pesquisa é economia da educação. 